\title{
Translating Performance: Educating Translators at the Interface of Oralate/Literate Cultures
}

\author{
Kobus Marais \\ University of the Free State, Bloemfontein, South Africa
}

\begin{abstract}
This paper draws on the linguistic anthropology of Marcell Jousse (1886-1961) and complexity theory for a holistic conceptualisation of human interaction. It proposes the propositional geste as the means of human interaction and then draws implications for the translation of oral style texts and for translator education. Grounding language practice in human interaction provides theoretical space to conceptualise various modes of interaction in a unified theory of language practice. It puts orality on a par with literacy. Translator education should base its curriculum on a view of translation, like the one propounded in this paper, which provides for all modes of human interaction. The particular modes of human interaction in Africa should be reflected in these curricula.
\end{abstract}

Keywords: translation education, linguistic anthropology, propositional geste, orality, language practice, curriculum

\section{Introduction}

(1) Somali poets prefer to put their poems on the Internet in a format that fans can listen to. There may or may not be written texts to provide "permanence" to these performances.

(2) In a small town in South Africa, a 10-year old boy reads the prescription on his grandmother's medication in English and tells her in Afrikaans what it says.

(3) An advertising company asks a professional translator to translate a written text for an Internet advertisement that will be presented in spoken form by a moving, computer-animated character on the screen.

As theorists with a disciplinary inclination, we often find it difficult to cope with these hybrid forms of human interaction. Our theories do not necessarily provide for this kind of complexity. Is it interpreting? Is it translation? Is it document design? Is it oral or written? We find it difficult to categorise these forms of human interaction. The argument in this paper will be that human interaction has always been and will always be of a hybrid nature and that we need a theory within which to conceptualise this wide variety of practices (see Marais, 2013 for a detailed discussion about complexity). Since the dawn of man, the anthropos has been gesticulating, mimicking, mumbling, signing, talking, later on writing and filming, and these day browsing the web, SMS-ing (short message service), emailing, etc.. Some of it, in the powerful areas of the world, may these days be done almost exclusively in writing, but pretty much of it is still done corporeally, orally, and aurally by means of the human composite as a whole. Whichever way one looks at it, human interaction is performed (Stacey \& Griffin, 2006, pp. 1-14) in a way that cannot be divulged from the bodily experience of individuals.

Kobus Marais, senior lecturer, Department of Linguistics and Language Practice, University of the Free State. 
In this paper, the author's aim is to work out the implications of the performative nature of human interaction for a curriculum for translator education. To achieve this goal, the author shall first argue for a theory of human interaction to inform this curriculum. The author shall briefly argue that the performative nature of human interaction should be conceptualised as part of the values that are assumed to underlie the proposed curriculum. Then the author shall offer some thoughts on the performative nature of, in particular, orality. Lastly, the author shall focus on aspects of a curriculum for translator education.

The author needs to contextualise three things before starting. First, the author sees this paper as part of a dialogue that has been invited by Tymoczko (2006), who advocates that voices from all over be heard in translation studies. The author's is thus a small voice from the southern tip of Africa taking part in this larger, postcolonial discussion. Second, the author takes as his point of departure Barnett's (1994) work on curriculum in which Barnett argued that before or besides talking about teaching and learning, strategy, classroom technique, etc., educators need to talk about the curriculum, the values underlying it, and what we want to achieve by this curriculum. Thirdly, Barnett generally follows Finnegan's (2007, p. 142) advice to deconstruct Africa as a unit. Indeed, it is no more a unit than Asia, America, etc., these are only constructs too. Neither "Africa" nor "orality" is a homogeneous concept. This observation does not only hold for the field of study itself, but also for the theoretical perspectives on this field of study. However, because the context of this article and its function require some sort of homogenising, the author shall for the sake of the discussion be talking about "Africa" and "orality" as opposed to Europe, the West, and literacy. As indicated above, the latter are obviously not homogeneous concepts. At the same time, the author's intent is not to discard Western translation theory, but to investigate complementary views and voices in the field in order to contribute to a theory of translation education that can truly account for more that only Western translation practices (Nel, 2008).

\section{Conceptualising Human Interaction}

In some of the author's previous work, he has argued in greater depth for a theory of human interaction to underlie translation studies and the translation curriculum (Marais, 2010). The author used the linguistic anthropology of Marcell Jousse (1886-1961) as a theoretical framework for this argument, arguing that writing should be deconstructed as either the pinnacle or the only form of human interaction. In this paper, the author wishes to expand on that theory by adding insight from the use of complexity theory in the study of organisations.

Jousse's main point has been that the anthropos is an interacting being. It interacts with other anthropos and the cosmos by means of gestes. For Jousse (2000, pp. 69-72), geste is a technical term for the corporeal-manual ways in which humans interact. Geste is much more than what is currently understood to be body language. All human interaction, according to Jousse, is of a bodily nature. The author was struck by the way in which Griffin (2006) conceptualised the sociology on which Griffin based his complexity theory of organizations in very similar terms. Griffin develops Meads' theory of human interaction in which the gesture is the basis of the systems theory on which organisational theory or cultural theory is built. The author could not yet determine any direct links between Meads and Jousse, but the similarities are too obvious to be accidental—seeing that Meads and Jousse worked in the same era. To the author's mind, the crucial point made by the arguments above is that all "social" or "human" phenomena are viewed as based in bodily or corporeal human interaction. Social phenomena, i.e., social systems, social institutions, societies themselves, emerge from the interaction of 
individual human beings (Griffin, 2006; Gu, 2008; Stacey, 2006). Social phenomena are not "phenomena" in themselves. They do not have a life or existence of their own. Rather, they emerge from interactions by individuals. They are performed by the anthropos.

The author shall work out this theoretical perspective on emergence in translation studies in full in another paper. Suffice it to say that, to understand human interaction, one needs a theory such as the above which opens up conceptual space for all modes of human interaction. Translation, as a particular instance of human interaction, is then conceptualised as operative in any of these modes, i.e., spoken or gesticulated, written or aural, and electronic or visual. Translation should thus be conceptualised theoretically broad enough to account for the performance of all kinds of human interaction. It should also be theoretically broad enough to account for all kinds of hybrid form of human interaction that may develop. In the section below, the author shall consider orality and hybrid forms of orality as one mode of human interaction, evident in but not exclusive to the African context.

\section{Translating Performance at the Interface of Oralate/Literate Culture}

The author now turns his focus to a discussion of performance in oral style texts, which he assumes to be an integral part of human interaction. In this section, the author shall basically make use of Finnegan's recent overview of the state of research on oral literature in Africa. Finnegan (2007) indicated that performance would, amongst others, be an important factor in understanding oral literature. The author shall also add some of Bandia's perspectives pertaining to performance and translation. The author must stress that this is not a discussion on performance per se, but an exploration of performance as it relates to human interaction as it relates to translation.

The author's main argument will be that what Finnegan is hinting at should be explored fully and is accounted for in Jousse's theory. This means that human interaction, in all its modalities, forms the field of study for language practice and for translation in the narrower sense. Translation/language practice thus has to reconsider its narrow definitions of dealing with written texts only. The fact of the matter is that in Africa, as Finnegan convincingly argues, as in the rest of humanity, as Jousse (2000) convincingly argued, the clear-cut difference between written and oral—and other modes of interaction — should always have been and have once again become suspect. Reality is never as neat as the human analytical abilities construct it.

On the basis of Austin, Finnegan (2007, p. 31) argued that things are done by words, not just said. She then argues that, for instance, the Limba uses formulas of which Jousse has also spoken to perform language acts. Jousse would have argued that all gestes, and thus all language, as instances of human interaction, do things - report, tell, confirm, etc.. The mere fact of doing is not the distinctive characteristic — the "what is being done" is the characteristic. The things that are done by means of language by the Limba are no different from what anybody else is doing. All people are using language in various forms and modalities to interact. The formality amongst the Limba to which Finnegan refers has as its motivation the fact that everybody in the community should know what has been said/done, seeing that there are no documents to preserve or record these interactions. Writing has made this type of oral documentation unnecessary. In this argument, Finnegan (2007, p. 41) thus acknowledged that people use language for many more purposes than rational statements, i.e., to interact with other in the full range of human abilities.

Finnegan (2007) quoted Chinweizu to argue that "[o]rature... is the root from which modern African literature must draw sustenance” (p. 1). This holds for other forms of interaction, too. Finnegan (2007, p. 2) 
focused on language as process and exchange, rather than on language as finalised textual product. The author would argue that in language practice, one should go one step further and focus on language as the expression of the anthropos rather than as a logical system on which one can perform mere logical operations. Also, placing human interaction within reality will provide an even wider and more fruitful context (Stacey, 2006). Finnegan (2007, p. 3) focused on verbalised action and the way people act with words to formulate and interpret the world. While this is true, one has to consider Jousse's indications that the word should not be the focus point of oral literature and that one should rather regard the propositional geste as the unit of oral interaction. On the basis of this statement, one should then question linguistics and language practice methods developed for written languages and those which do not apply to "oral” languages. What we need is a "linguistics of orality" (Siennaert, personal correspondence, January 13, 2009) or a "language practice of orality". This same question is anyway being asked in translator education too and most of the consensus is that the unit of translation is not the word, but the sentence, or at least the phrase, in oral terms, a unit of breath (Siennaert, personal correspondence, January 13, 2009).

One form by means of which oralate people display their consciousness of artistry is by using storytelling as a means of ordering their experience (Finnegan, 2007, p. 44; also see Marais, 1998). Storytelling may have various functions, amongst which socialising and leisure could be counted, but that does not mean that it is not a form of art (Finnegan, 2007, p. 44). The aesthetic does not exclude function and function does not exclude the aesthetic. What is important as far as oral stories are concerned is that the stories are not merely a matter of verbal form or content, but of performance, i.e., repetition, reduplication, mimicry, gesture, onomatopoeia, and ideophones (Finnegan, 2007, p. 45). Finnegan (2007, pp. 45-69) further expounded the features of performance in oral storytelling by focussing, for instance, on the fact that the audience plays an important role (see also Nel, 2008). Narratives are performed not only by words, but also by sonic patterns, visual gestures, facial expressions, interactions with the audience, singing, dancing, and dance-evoking movements. Finnegan (2007, p. 69) concluded that multi-modality rather than mono-modality is the order of the day. This is precisely what Jousse claimed decades before her.

A characteristic of oral literature is that, being oral, its existence depends on performance, that is, on a specific occasion or occasions, on the interaction with a specific audience, on a specific set of circumstances in a way that a permanent written text does not (Finnegan, 2007, p. 115). The performance is necessarily an event at a particular time, in a particular space, on a particular occasion, with a particular audience-it is particular. Performance-oriented scholars have drawn attention to the "event"-based nature of oral art. It is not so much spatial text as "story-telling event” or "communicative event”, a temporal event (Finnegan, 2007, p. 115). Oral literature essentially depends on people's co-activities. Once a story is settled on paper, once it exists in space, the temporality of its performance has become of little consequence.

Oral stories are not usually told in linear-single-line mode, but one has various people contributing to the story and this is not seen as interruption. Group participation and interchange are the order of the day (Finnegan, 2007, p. 126). What strikes the author from these pieces of information is that oral language is situated in society much more than written language, but it is also situated in bodyliness. It is a mode of interaction in which the full scope of human geste is utilised. In this paper, the author does not want to enter 
into a debate as to how to capture oral literature in other modes such as writing (Conolly, 2002). The author merely wishes to point out that translation students need to become competent in communicating in an intermodal or multimodal way.

Current views on orality represent a move away from mere verbally texted dimensions into an appreciation of voiced and sonic qualities, the auditory—sometimes multisensory—relations between participants, and the active dialogues of performance (Finnegan, 2007, p. 191). The evanescent nature thereof (Ong, 1995) makes oral texts all the more valuable, although one should note that even oral texts have stability in the memory of their performers and the society in which they are performed. It should also be noted that the use, by story-tellers, of beads and counting necklaces allows them to play with the texts (textus: weaving), to omit or not to omit passages according to the wish or need of the audience (Siennaert, personal correspondence, January 13, 2009). Any performance is a compromise. It is an intelligent adaptation of the tradition within unique situations which are structured by a confluence of several factors. This means that textuality is co-dependent and co-present (Finnegan, 2007, p. 192). Immediacy and permanence are mixed in the newest approach to orality for which the concept of mental text has been devised (Finnegan, 2007, p. 194). The point here is that a written text is merely a technologically conditioned representation of a set of propositional gestes. It is not the gestes. The gestes are in the human beings, not in the texts. One may even need to go further to talk about corporeal texts not only mental texts, because the "texts", the anthropos's expressions, reside in the anthropos itself in the very fibre of the anthropos, not in part of it. If one takes Jousse seriously, memory has a similar function as text, giving permanence to oral narrative. Finnegan (2007, p. 211) was also challenging language as single-voiced (see also Greenall, 2006), abstract, and referential. Multi-modality may not be a secondary feature of language, but central to its usage. What Finnegan was proposing is just what Jousse had already expounded. Finnegan is decentring linguistic expression and giving the rich, multimodal expression by the anthropos its rightful place. With this, one should remember that multimodality is a construct made possible by the development of technology. For the anthropos without technology, there is only its body and its mechanics that can be used for purposes of expression.

Because oral literature is realized in performance, the performance is part of a larger social whole, a context which is socially, culturally determined (Finnegan, 2007, p. 79). In oral literature, literary devices are not merely aimed at embellishment, but are an integral, though flexible, part of the realisation of the work of art. Function and aesthetics combine to create meaning. This means that translators should neither focus merely on words, nor on language only, but on the whole embedded context (Finnegan, 2007, p. 79). At this stage, the point the author wants to make is that translator students should be exposed to orality so that they may, at least, take note of the fact that orality features in many interaction situations and that written texts may have had oral origins and residues of that orality. These origins could, to some extent, be regained in translation, if the translator is aware of the features of oral interaction. Bandia (2008) had claimed that the very function of many African writings is an intermodal translation, putting the oral narratives to book in order to reclaim the conceptual space of African thought. It is an act of decolonisation and reparation. Educating translators to be sensitive to performance is thus a matter of ideological importance in, at least, the African context.

Jousse has made a clear distinction between orally composed texts recorded in written format and texts composed in writing and recorded in writing. The precise ways of dealing with the difference fall outside the ambit of this paper. The main point is that either in transcribing oral narratives in writing, which can be viewed as 
intersemiotic translation, or in translating oral narratives between languages, knowledge of orality can only enhance the quality of translation and pay justice to orality as a primary mode of interaction, not a secondary one. At least, the boundaries between the oral and the literate are fading. Translators need to be prepared for this development.

\section{Towards a Curriculum for Translator Education in Africa}

Against the background of what they interpret as tendencies towards a technical and economic bias in higher education, Barnett and Coate (2005) argued that the curriculum as the embodiment of decisions on the ideals of lecturers in a particular field of study has not received due attention. The author has argued elsewhere (Marais, 2010) that this criticism also holds for translator education. Taking his lead form Barnett and Coate, the author is conceptualising a curriculum in three facets, i.e., knowledge, being, and action (Barnett \& Coate, 2005, pp. 53-68). They argued that a curriculum in the humanities may contain a larger focus on knowledge with being afforded less emphasis and action the least (Barnett \& Coate, 2005, pp. 73-75). Against this theoretical background, the author shall thus discuss the content of a translation curriculum (knowledge), the values underlying it (being), and the skills students are supposed to have on completion of their studies (action).

Firstly, as far as knowledge is concerned, we need, for translator education, a theory of translation that will not limit human interaction to any modality. The existence of non-written forms of expression all over the world, be it in the form of oralate, "non-literate" performers or in the form of multimodal options provided by the most recent technology, has to be accounted for in this theory. The conceptual difference between translation and interpreting will have to be revisited, especially in the African context. It is a distinction that only holds where one draws a basic distinction between oral and literate skill, which for various reasons does not suffice for the African context. The author's aim is not to reduce translation studies to an anthropological perspective or approach. It is rather to find some form of conceptualisation broad enough to accommodate the wide variety of modes of interaction and the hybrid forms in which this interaction occurs all over the globe. It is to conceptualise of human interaction in ways both "non-technological", where multimodality dominates in the oral style of interaction, and "highly technological", where multimodality is becoming a reality on, for instance, the Internet. Our theory of translation/interpreting will then be better able to accommodate the variety. The author is well aware of the dangers of limiting his conceptualisation to the discipline of anthropology. This is not what he wants to do. The author actually wants to conceptualise human interaction as taking place in reality. He wants to use Jousse's conceptualisation, which argues that the anthropos expresses itself in a number of modes, as the common denominator for studying the wide variety of human interactions or expressions, the wide variety of modes in which this occur, and the wide variety of cultural-specific forms that these interactions take.

The second point the author wants to stress concerning the knowledge base that he thinks should underlie translator education is that we need much more research on various aspects of a conceptualisation of translation to inform translator education in Africa. The conceptual space created above needs to be filled with empirical evidence from as wide a variety of contexts as possible. This emerging evidence should then challenge our conceptualisation of translation studies and, concomitantly, translator education. We need research on the context of this education, on the curriculum we need to expose our students to, on basically every aspect of translator education. The author shall comment on this again, but it is essentially an ideological struggle for the soul of Africa. We, in Africa, need to research the ways in which people express themselves in African cultures. 
Thirdly, orality has to form part of the curriculum of translation education in Africa. African translators who are imbibed in a literate notion of interaction will not serve the interaction between people on the continent. Translators who have to localise material on, for example, AIDS (Acquired Immune Deficiency Syndrome) and who do not have knowledge and skill about orality will not touch the target audience where they need to be touched. What is needed is a type of education that will allow language practitioners to deal with the multimodality of human interaction, not one that limits the education to one mode or one cultural expression.

Lastly, and perhaps most importantly, this is part of a decolonising process. It is part of a deconstructing process which does not hold for Africa only, but for the whole third world. It is a matter of finding one's voice. On the back of international companies and organisations working in Africa, ideology rides piggy-back into the hearts of African people. Not all of this can and need to be discarded. However, if African translators are not educated in the power play involved in translation, they will merely perpetuate certain ideologies and degrade Africa's own ways of interaction. Most probably the most important contribution that a transformative translator education can make is an anti-colonial one. Especially as far as colonising the mind is concerned. By being aware of issues such as colonialism, power, etc., translators could influence the types of texts being translated but also the way translations are tackled—it could also assist in making voices heard, telling stories.

As far as the values of translator education are concerned, the author has argued extensively in a number of articles for wisdom to be the ultimate value, a value that includes other values, to strive for (Marais, 2008, 2009). He shall not repeat the arguments here but merely point out that translation competence is not a mechanical competence. Being a translator requires the ability to weigh, to judge, i.e., wisdom. In order to operate within such a complex environment, students need more than mechanical competence. They need knowledge and values to be able to make ethically responsible choices not only on the level of linguistics and texts, but also on the level of culture and ideology.

At this stage, thirdly, there seems to be quite a bit of consensus on the types of skill that translators need, i.e., linguistic, textual, pragmatic, and strategic knowledge (Angelelli, 2009). These types of knowledge, it seems, assumes knowledge of culture and ideology, which can also be conceptualised as part of the types of skill that translators need. The author needs to point out that these forms of knowledge are to be regarded as performative knowledge, i.e., skill. Students need to be able to operate in two languages, create different types of text, function in different pragmatic contexts, and make certain strategic choices.

On the basis of the above, the author is presenting the following outline of a curriculum as a case in point. In this case, the needs of analysis and negotiations with the industry have been done in depth and are kept up to date by regular peer reviews. The author thus starts off with the general aim of this curriculum: The curriculum aims at educating wise translators who will have the knowledge and skill to produce functionally efficient translations to the benefit of society.

This aim contains not only the knowledge, values, and skills deemed necessary for translators. It also takes an ethical point of view of situating translator education within the notion of the benefit of society. What the benefit may be is, as are all ethical issues, to be debated. Also, the author has made a choice for a particular approach to translation, i.e., functionalism. This does not exclude the need for exposing students to other theories, as the author shall illustrate later, but it does acknowledge the fact that, for the education of translators, one needs an "operating theory" (Angelelli, 2009). In this particular case, the author has in mind the postgraduate courses, 
i.e., a postgraduate diploma, a BA Hon., and a structured master's. Please note that this discussion refers to the South African situation where the postgraduate diploma aims at enhancing skill for the profession. The honours degree is a preparation for the master's, focussing on research and a deeper understanding of the field of study. At master's level, students can do a dissertation master's which aim only at research. They can also do a structured master's which has a dual aim, i.e., preparation for the profession as well as a deepened understanding of the field of study. Also note that the last digit in the codes below indicates the credit value of the module in the following way: The number times four provides the credits of the module. In the South African system, a credit refers to 10 notional learning hours. A 16-credit course thus implies 160 hours of learning, i.e., reading, classroom activities, assignments, and assessment.

In Table 1, the author presented three types of courses, i.e., generic modules that all students have to take, as well as theoretical and practical modules that students specialising in translation have to take. The generic modules provide the student with theoretical background on language, text, and culture, the three basic competencies set out above that translators should have. In terms of the knowledge and values that the author has argued translators should have, these modules will contain significant amounts of theory on orality and pragmatics.

Table 1

Outline of Generic and Translation Modules

\begin{tabular}{|l|l|l|l|l|}
\hline & Postgraduate diploma & Honours & Master's: year 1 & Master's: year 2 \\
\hline \multirow{2}{*}{$\begin{array}{l}\text { Generic } \\
\text { modules }\end{array}$} & $\begin{array}{l}\text { TPP614 } \\
\text { Cultural, textual, linguistic, } \\
\text { and policy aspects of } \\
\text { language practice }\end{array}$ & $\begin{array}{l}\text { TPP634 } \\
\text { An introduction to culture, } \\
\text { text, and language }\end{array}$ & $\begin{array}{l}\text { TNM624 } \\
\text { Research methodology }\end{array}$ & TPP734 \\
Culture, text, and language & $\begin{array}{l}\text { TNM724 } \\
\text { Research methodology }\end{array}$ \\
\hline $\begin{array}{l}\text { Theoretical } \\
\text { modules }\end{array}$ & $\begin{array}{l}\text { TPP614 } \\
\text { trategies for solving } \\
\text { translation problems }\end{array}$ & $\begin{array}{l}\text { TPP614 } \\
\text { Strategies for solving } \\
\text { translation problems }\end{array}$ & $\begin{array}{l}\text { TPP714 } \\
\text { Theoretical approaches to } \\
\text { translation }\end{array}$ & $\begin{array}{l}\text { TPP754 } \\
\text { New developments in } \\
\text { translation studies }\end{array}$ \\
\hline $\begin{array}{l}\text { TPP774 } \\
\text { Models in translation } \\
\text { research }\end{array}$ \\
\hline $\begin{array}{l}\text { Practical } \\
\text { modules }\end{array}$ & $\begin{array}{l}\text { TPP624 } \\
\text { The translation of } \\
\text { communicative texts }\end{array}$ & $\begin{array}{l}\text { TPP624 } \\
\text { The translation of } \\
\text { communicative texts }\end{array}$ & $\begin{array}{l}\text { TPP724 } \\
\text { The translation of technical } \\
\text { texts }\end{array}$ & $\begin{array}{l}\text { TPP734 } \\
\text { The translation of technical } \\
\text { and literary texts }\end{array}$ \\
\hline
\end{tabular}

Secondly, the series of modules pertaining to translation theory start off with issues of translation strategy. These modules, on the level of postgraduate diploma and honours, address the theory of translation strategies on the micro, meso, and macro levels, i.e., linguistic, textual, and cultural/ideological issues. It is embedded in a functional approach to translation. On the master's level, the theory then addresses the major theories/perspectives on translation, i.e., standard theoretical work of which students working in a field should take cognisance. The module has units pertaining to linguistic/pragmatic theories, functionalism, cultural theories, and sociological theories. In selecting the reading work for these, standard international readings are chosen. Care is taken to include reading work from the African context, e.g., Diop, Bandia. In the second year of the master's, the theoretical modules have two aims, i.e., exposure to the newest developments in translation studies and theoretical models and methodologies for research in translation studies. In the former, we are currently offering readings on agency, narrative theory, Tymoczko's ideas about enlarging the field of translation studies, and geopolitical theories of translation, e.g., Gentzler. Here we also offer some of the more 
difficult standard writings on translation studies, i.e., Walter Benjamins, Derrida, etc.. This may obviously change as the field develop. In the other module, we are focussing on descriptive translation studies and corpus studies. This is where the expertise in the department is, not an indication as to the only two important models for translation research. In this way, once a student has completed even a structured master's degree, she should have an overview of the field of translation studies.

In the practical modules, we are increasing the level of difficulty of the texts from communicative texts to technical and literary translation in the second year of the masters. The communicative texts we start off with are not generally communicative texts, i.e., e-mails, newspaper reports, which we do on undergraduate level. They are "subject-specific" communicative texts, e.g., economic articles in a journal published for the general public or tender documents which contain some technical jargon, but which still aim at the general public as readers. It is only on master's level that we provide students with purely technical texts, i.e., texts written for a specialist/professional audience. This also includes literary translation. All practical assignments are required to be accompanied by essays in which theory and practice are expected to be integrated and annotations in which particular strategies for translation have to be explained or defended.

What is not visible from the table is that students are able to combine their modules in translation with other modules in language practice, i.e., editing and document design, language technology, terminology/lexicography, language management, or interpreting. In the South African context, where the market does not require that much specialisation, we found a broader education to be of more use to students.

The author shall now briefly discuss the objectives and outcomes of two modules, one theoretical and one practical. The author has chosen TPV754, which is the module from the second year of the master's course called "New Developments in Translation Studies".

The objectives of this module are to: (1) allow students to shape their own identity as translators by exposing them to a variety of translation theories; (2) awaken in students a critical awareness of the implications of each theoretical position; (3) allow students to reflect on the implications of translation theory; (4) provide students with opportunities where they are confronted with the choices implicit in each theory of translation; and (5) support students in becoming professionals who are able to integrate thought and action.

On finishing this module, students will be able to: (1) critically reflect on the implications of translation theory and communicate their reflection; (2) critically explain their own concept of translation; (3) make choices to solve translation problems; and (4) conduct themselves as professional translators.

The practical module the author has chosen is TPV734, which is also a module from the second year of the master's course called “The Translation of Technical and Literary Texts”.

The objectives of this module are to: (1) allow learners to learn unconsciously by doing translation work; (2) allow learners to learn reflectively by relating the translation work to aspects of theory; (3) provide the necessary opportunity for translation practice in technical and literary translation; and (4) enhance learner's self-image as professional translators.

On finishing this module, students will be able to: (1) critically reflect on their own translation work and communicate their reflection; (2) do translation work in genres of technical and literary language, e.g., medical texts, advertisements, economic texts, literary texts; (3) critically explain their own concept of the translation; and (4) conduct themselves as professional translators. 
These knowledge, values, and skills need to be facilitated in students by means of particular teaching and learning strategies. For this, Kiraly and others have provided ample theory and practical guidance. Suffice it to say that the pedagogy chosen by lecturers will carry the knowledge, values, and skills embedded in the curriculum.

\section{Conclusions}

In conclusion, the author has argued for a conceptualisation of translation that is broad enough to cater for all forms and modes of human interaction. The author has indicated, by using performance as an example, how current theories of translation do not necessarily accommodate all phenomena relating to intercultural interaction.

The author is convinced that the curriculum for translator education in Africa is a battleground for the soul of Africa. Translator educators need to consider and reconsider the curriculum devised for translator education. This curriculum is in urgent need of contextualising. It is also in urgent need of holism, viewing the anthropos and its interaction with others as a whole. It is in need of interdisciplinary cooperation to revalue the whole.

\section{References}

Angelelli, C. V. (2009). Using a rubric to assess translation ability: Defining the construct. In C. V. Angelelli, \& H. E. Jacobson (Eds.), Testing and assessment in translation and interpreting studies. Amsterdam: Benjamins.

Bandia, P. (2008). Translation as reparation: Writing and translation in postcolonial Africa. Manchester: St. Jerome.

Barnett, R. (1994). The limits of competence: Knowledge, higher education and society. Buckingham: SRHE \& Open University Press.

Barnett, R., \& Coate, K. (2005). Engaging the curriculum in higher education. Berkshire: Open University Press.

Conolly, J. (2002). Memory, media and research: Mnemonic oral-style, rhythmo-stylistics and the computer. Alternation, 9(2), 156-178.

Finnegan, R. (2007). The oral and beyond: Doing things with words in Africa. Oxford: James Curry.

Greenall, A. K. (2006). Translation as dialogue. In J. F. Duarte, A. Assis Rosa, \& T. Seruya (Eds.), Translation studies at the interface of disciplines. Amsterdam: John Benjamins.

Griffin, D. (2006). The emergence of leadership: Linking self-organization and ethics. London: Routledge.

Gu, Y. (2008). The Chinese language as a multi-dimensional city of history and mystery-An ecological model for knowledge engineering. Proceedings of the XVIII FIT International Conference, Shanghai, China.

Jousse, M. (2000). The anthropology of geste and rhythm. (E. Siennaert \& J. Conolly, Trans.). Durban: Mantis Publishing.

Marais, J. (1998). Representation in Old Testament narratives. Leiden: E.J. Brill.

Marais, J. (2008). The wise translator: Reflection on judgement in translator education. Southern African Linguistics and Applied Language Studies, 26(4), 471-477.

Marais, J. (2009). Wisdom and narrative: Dealing with complexity and judgement in translator education. Acta Theologica Supplementum, 12, 217-233.

Marais, J. (2010). I have rhythm therefore I am: Exploiting the linguistic anthropology of Marcel Jousse in exploring an African curriculum for translation studies. The Translator and Interpreter Trainer, 4(1), 33-46.

Marais, J. (2013). Translation theory and development studies: A complexity theory approach. Routledge: New York

Nel, P. J. (2008). Indigenous knowledge systems and language practice: Interface of a knowledge discourse. Journal for New Generation Sciences, 6(3), 94-108.

Ong, W. J. (1995). Orality and literacy: The techologizing of the word. Routledge: New York.

Stacey, R. (2006). Ways of thinking about public sector governance. In R. Stacey, \& D. Griffin (Eds.), Complexity and the experience of managing in public sector organizations. London: Routledge.

Stacey, R., \& Griffin, D. (2006). Introduction. In R. Stacey, \& D. Griffin (Eds.), Complexity and the experience of managing in public sector organizations. London: Routledge.

Tymoczko, M. (2006). Reconceptualizing translation theory. Integrating non-western thought about translation. In T. Hermans (Ed.), Translating others (Vol. 1, pp. 13-32). Manchester: St. Jerome. 